East African Medical Journal Vol. 81 No. 7 July 2004

QUALITY OF LIFE IN MALE CANCER PATIENTS AT KENYATTA NATIONAL HOSPITAL, NAIROBI

W.O., Mwanda, MBChB, MD, Senior Lecturer, F. K. Abdallah, MBChB, MMed, Lecturer, Department of Haematology and Blood Transfusion, A. Obondo, BA., MD., PhD, Lecturer, Department of Psychiatry, College of Health Sciences, University of Nairobi P.O. Box 19676, Nairobi and F.M. Musau, MD, Consultant Paediatrician, Kenyatta National Hospital, P.O. Box 20723, Nairobi, Kenya

Request for reprints to: Dr. W.O. Mwanda, Department of Haematology and Blood Transfusion, College of Health Sciences, University of Nairobi, P.O. Box 19676, Nairobi, Kenya

\title{
QUALITY OF LIFE IN MALE CANCER PATIENTS AT KENYATTA NATIONAL HOSPITAL, NAIROBI
}

\author{
W. O. MWANDA, F. K. ABDALLAH, A. OBONDO and F. M. MUSAU
}

\begin{abstract}
Background: The quality of life of cancer patients is likely to be influenced by psychological reactions of the cancer patients yet there are no documented issues related to quality of life in cancer patients in Kenyan hospitals.

Objective: To investigate issues which affect the quality of life in male cancer patients. Design: Prospective cross sectional study.

Setting: Kenyatta National Hospital, Nairobi, Kenya.

Methods and subjects: Cancer patients above 12 years of age were interviewed during the course of their stay in the hospital, specifically to gather information on; semi structured questions and a modified Beck's 24 item depression inventory with a view to solicit for their reaction on issues which pertains to quality of life.

Main outcome measures: Age group, level of education, tribe, geographical place (province) of birth, chief complains, main concerns, views on doctors, contact with psychiatrist and psychologist, the anatomic site of cancer, treatment given and responses on modified Beck's depression inventory.

Results: Forty two patients were studied, their age range 13-72 years, mean 43.2 and peak 13-26 years. Forty seven per cent of cases had no formal education. The cancers were gastrointestinal tract $33 \%$, blood and lymphoid tissue $(26 \%)$, bone and muscle $(\mathbf{1 1 . 9 \%})$, skin $(\mathbf{9 . 4 \%})$ and genitourinary tract $(4.8 \%)$. Treatment given was chemotherapy, radiotherapy and surgery. Ninety three per cent were unable to cope. Chief complaints were pain, inability to work, feeling miserable and concerns were families, health and work retardation. Modified Beck's depression score was $\mathbf{2 0 \%}$, with major issues being; work retardation, insomnia, weight loss, and anorexia. Most affected were, age group 27-35 years (and least 13-26 years), uneducated, living in Nairobi (city), having carcinomas, treatment with combined surgery and radiotherapy. Low education level and residence in Nairobi coped poorly. Radiation therapy group appeared to cope better than other modalities.

Conclusion: The issues affecting the quality of life of male cancer patients stated were pain, inability to work, poor coping with cancer and psychological reactions of work retardation, insomnia, weight loss, fatigability and depression. Gambling, suicidal ideas and social withdrawal were minimal. Other concerns were families, health and work.
\end{abstract}

\section{INTRODUCTION}

The issues that affect the quality of life of a person with a disease are mainly the disease itself and patients' reactions to that disease(1). In the case of cancer usually it is not just having cancer that elicits problems, it is also the implied connotations that may be attached to the disease such as pain, disfiguration, hospitalisation, loss of work ability, disability and fear of death(2). The ensuing responses depends on how the individual deals with stressful situations and the nature of the stresses imposed by the manifestations and course of the cancer(2-4). It is possible that patients' reactions to cancer may vary remarkably in different parts of the world depending on age group, cultural, ethnic, social, economic and educational factors(5). In most countries, the word cancer is a recent concept and many local languages do not have the equivalent words for cancer. Previously, physicians avoided telling the patients their diagnosis because of the admonition that "he will kill himself if he knows he has cancer" $(6,7)$. However, accurate data on these issues including declaration of the diagnosis are scarce, and the risk of suicide as a result of discussing the patient's diagnosis with him seems to be exaggerated. 
Furthermore, there are other aspects of cancer that impart on the quality of life differently from other diseases. These aspects relate to the histological type, anatomical sites and the treatment of cancer, which may entail various combinations of surgery, radiotherapy, chemotherapy and supportive care(8-11). All these have been shown to demand extensive psychological and physical adaptation to maintain good adjustment $(6,7)$. For instance, it is envisaged that surgical loss of the body part and functions impact serious concerns transiently or permanently. Other corrective and rehabilitative measures are also of relevance as some patients, due to adverse psychological reactions just never attain full return to the expected function and occasionally, a patient becomes a psychological invalid despite cure of cancer(12). The interpretation, for instance, that being given radiotherapy to many people means that the outlook is poor and chemotherapy demands a high level of patient co-operation and commitment with its established complications and uncertain outcome would impose further particularly psychological reactions to the patient(13).

Also a patient who has had a prior history of psychiatric illness may experience an exacerbation of mental symptoms in the course of cancer. Indeed the most common of emotional distresses is anxiety and depressive symptoms $(14,15)$.

It is also recognised that patients attitude to the medical staff particularly the doctors have an influence in their coping and psychological impact. The patient must have not only a personal involvement but also full acceptance of the sick role(16).

It is mandatory that as soon as the diagnosis of cancer is made and before a cancer patient is commenced on any modality of treatment for the cancer, an in-depth counselling be done. The potential issues that will affect the quality of life particularly psychological ones should be addressed in a systematic manner for the proper total management of the cancer patient. Just as appropriate history and laboratory data are assembled while prescribing medication, collection of data to determine the quality of life issues should be assessed.

These should enable, in the majority of patients, honest discussions about the subsequent management of events. However, it is desirable to have local dimensions of some of the ensuing issues of cancer patients against a unique background of knowledge, regional, cultural, ethnic, social, economic and educational diversity some of which are known to influence the reactions to cancer(17). Indeed it is abundantly noted that there is no gold standard to estimate people's subjective quality of life. However, whatever makes up quality of life an illness may have variable impact that can be predicted by instruments or scales from different societies. Quality of life encompasses a broad spectrum of issues in cancer care including physical, cognitive, emotional and psychological aspects. It is documented that emotional distress is very common in cancer patients. Research has revealed a high prevalence of psychiatric illness in a variety of populations of cancer patients (2-5). Adjustment disorders is also reported to be common(3). This study attempts to identify quality of life issues particularly the psychological reactions in male cancer patients being treated as in-patients in a Kenyan setting.

\section{MATERIALS AND METHODS}

This was a prospective cross-sectional study set at the Kenyatta National Hospital between June 1999 and June 2000. In accordance with the principles of good clinical practice and declaration of Helsinki, all patients gave consent verbally or signed a consent statement.

Eligibility: Any male in-patient who had histologically proven cancer, and was older than 12 years.

Ineligibility: No histological proof of cancer and unable to or declining to consent for participation in the study.

Study Protocol: All eligible patients were interviewed in the usual medical clinical evaluation based on semistructured questions. Of necessity were ascertainment of age, tribe, geographical (province) place of birth, questions on the main concerns, views on doctors, contact with psychiatrist and psychologist. Also verified and noted were the initial anatomic site of cancer, modalities of treatment given or planned and responses on aspects of modified Beck's 24 item depresion inventory (sample appended).

Symptom scores: The presence and level of factors that affect quality of life were evaluated using graded or valued semi-structured questions and on modified ratings of Beck's depression inventory $(18,19)$. The items, 24 in total, describe symptoms related to the presence of reactive nature and depression and respondents rate the degree with which they experience each manifest or symptom. Possible scores per symptom ranged from 0 to 3 ; with the overall scores for all the 24 items expected was 72 while 0 (zero) was the least lower scale indicating no person gave any score for any symptom. (The study cases scores; possible maximum 3 times 24 symptoms equivalent to 72 ), while for all the 42 patients; every individual 3 times 42 giving 42 times 72 equivalent to 3024 symptoms with maximum of 3 points per symptom and all the 42 cases to 126 .

\section{RESULTS}

In the period of the study, 42 male cancer patients were evaluated and the results presented.

Characteristics of the study cases: Of these 42 patients, only one case had a difference in age from time of diagnosis to evaluation as he was 66 at first diagnosis and interviewed at 72 years. Out of Kenya's 42 tribes only three had significant numbers among the male cancer in-patients. These were Kikuyu, Luhya and Kamba. The level of formal education represents perhaps what is a feature of the Kenyan community.

The anatomical site or tissue type of cancer were gastrointestinal tract (GIT), blood and lymphoid tissue, bone and muscle, skin, genital urinary tract (GUT) while main treatment modalities were chemotherapy, surgery and radiotherapy. These characteristics of the studied cases are presented in Table 1. 
Table 1

Characteristics of the study cases

\begin{tabular}{|c|c|c|}
\hline Characteristic & Frequency & $(\%)$ \\
\hline \multicolumn{3}{|l|}{ Major tribe documented } \\
\hline Kamba & 4 & 9.5 \\
\hline Kikuyu & 24 & 57.1 \\
\hline Luhya & 9 & 21.4 \\
\hline Others & 5 & 11.9 \\
\hline \multicolumn{3}{|l|}{ Birth place (Province) } \\
\hline Nyanza & 6 & 14.3 \\
\hline Western & 6 & 14.3 \\
\hline Central & 13 & 31.0 \\
\hline Rift Valley & 5 & 11.9 \\
\hline Nairobi & 2 & 4.8 \\
\hline Eastern & 9 & 21.4 \\
\hline Coast & 1 & 2.4 \\
\hline \multicolumn{3}{|l|}{ Last grade completed in education } \\
\hline Not educated & 5 & 11.9 \\
\hline Primary & 19 & 45.2 \\
\hline Secondary & 15 & 35.7 \\
\hline College & 3 & 7.1 \\
\hline \multicolumn{3}{|c|}{ Main anatomical site/ tissue type of cancer } \\
\hline GIT & 15 & 35.7 \\
\hline Blood and lymphoid tissue & 11 & 26.2 \\
\hline Carcinomas & 6 & 14.3 \\
\hline Miscellaneous & 10 & 23.8 \\
\hline \multicolumn{3}{|l|}{ Treatment given } \\
\hline Surgery & 8 & 19.0 \\
\hline Chemotherapy & 13 & 31.0 \\
\hline Radiotherapy & 2 & 4.8 \\
\hline Combination & 15 & 35.7 \\
\hline Awaiting treatment & 4 & 9.5 \\
\hline
\end{tabular}

Age (years) Range $=13-72$, Mean $=43.2(\mathrm{SD})$, Median $=44.5$

Complaints and main concerns: Pain, inability to work and misery were the chief complaints. The majority were concerned about their illness and the main specific concerns were finances, family, health and work. The relative frequencies are shown in Table 2.

Coping: The results show that the majority of the cancer patients were coping poorly with $7 \%$ observing that they were able to cope while $93 \%$ were not able to cope. Varied degrees of coping were observed in accordance to level of education, province, anatomic site, and treatment modality.
Table 2

The documented attributes on semi-structured questions. The observed outcome of the studied cases

\begin{tabular}{lcc}
\hline Questions Response & Frequency & $(\%)$ \\
\hline Chief complaints & & \\
$\quad$ Pain & 9 & 21.4 \\
$\quad$ Cannot work & 18 & 35.7 \\
$\quad$ Misery & 15 & 35.7 \\
Main concerns & 1 & \\
$\quad$ Not concerned & 14 & 2.4 \\
$\quad$ Health & 2 & 33.3 \\
$\quad$ Finances & 25 & 4.8 \\
$\quad$ Family, health and work & & 59.5 \\
Coping with cancer & 3 & 7.1 \\
$\quad$ Able to cope & 39 & 92.8 \\
$\quad$ Not able to cope & & \\
View about the doctors & 5 & 11.9 \\
$\quad$ Are slow & 2 & 7.8 \\
$\quad$ Do not understand them & 2 & 76.2 \\
$\quad$ Do not update on status & 3 & \\
$\quad$ Doing their best & 32 &
\end{tabular}

Beck's 24 item depression inventory: Beck's depression inventory symptoms scores; cases and the expected

\begin{tabular}{lccc}
\hline & Mean & Median & Total (\%) \\
\hline $\begin{array}{l}\text { Expected overall } \\
\text { scores }\end{array}$ & 14.24 & 13 & $3024(100)$ \\
Actual study scores & 72 & 72 & $598(19.8)$ \\
\hline
\end{tabular}

The modified Beck's depression inventory expected overall score was $72(100 \%)$ while the study score was 14.24(20\%), (Table 3). The study scores as observed by study attributes were as follows:

Age group: The depression level score in descending order were 27-35, 52-60 and 61 and plus old 14-26, 36-42 and 43-51 years. Insomnia, work retardation and anorexia sited as the main symptoms.

Tribe: Of the documented tribes the scores on the depression scale in a descending order were Luhya Kikuyu, Kamba and others.

Educational level: The education levels and scores revealed that not educated and primary level scored highest in the depression index while college level of education scored least. 
Provincial: Of the Kenya's eight provinces, all except one were represented. The province score from highest to least in depression scale were: Nairobi, Coast, Western and Eastern Nyanza, Central and Rift Valley.

Anatomic site: With respect to anatomic site or of tissue type of cancer, the site of the disease that showed with most symptoms of depression were miscellaneous and carcinomas while those with less scores were GIT, blood and Iymphoid tissue.

Treatment modality: The depression inventory scores in decreasing order were as follows: surgery plus radiotherapy, chemotherapy alone, and surgery plus chemotherapy plus radiotherapy (combination of all modalities) chemotherapy plus radiotherapy, surgery alone and those awaiting therapy.

Symptom score on the modified Beck's 24 item depression inventory: The modified Beck's depression inventory symptom scores of cases and the expected for best five symptoms, and least five symptoms are shown in Table 1. It appears that in this rating, physical signs and symptoms were pronounced and the main issues were work retardation, weight loss, fatigability while driven issues such as gambling, suicidal ideas, social withdrawal were minimal.

Table 3

Individual symptom scores for the five highest and five lowest

\begin{tabular}{lccc}
\hline & Mean & Medial & Overall \\
Expected score per symptom & 3 & 3 & $126(100)$ \\
\hline Highest scores (symptoms) & & & $70(55.6)$ \\
$\quad$ Work retardation & 1.67 & 2 & $57(45.2)$ \\
Insomnia & 1.36 & 1 & $51(40.5)$ \\
Weight loss & 1.21 & 1 & $50(39.7)$ \\
Anorexia & 1.19 & 1 & $47(37.3)$ \\
Fatigability & 1.12 & 1 & $7(5.6)$ \\
5 least scorers (symptoms) & 0.17 & 0 & $4(3.2)$ \\
Drug indulgence & 0.1 & 0 & $3(2.4)$ \\
Social withdrawal & 0.07 & 0 & $3(2.4)$ \\
Self-accusations & 0.07 & 0 & $0(0)$ \\
Suicidal ideas & 0 & 0 & \\
Gambling & & & \\
\hline
\end{tabular}

Appendix 1

Beck's depression inventory symptoms scores of cases and expected study score

\begin{tabular}{|c|c|c|c|}
\hline Symptom & Mean & Median & Score $(\%)$ \\
\hline Total Study Score & 14.24 & 13 & $598(19.8)$ \\
\hline Expected Overall score & 72 & 72 & $3024(100)$ \\
\hline Expected score per symp & 3 & 3 & $126(100)$ \\
\hline Work retardation & 1.67 & 2 & $70(55.6)$ \\
\hline Insomnia & 1.36 & 1 & $57(45.2)$ \\
\hline Weight loss & 1.21 & 1 & $51(40.5)$ \\
\hline Anorexia & 1.19 & 1 & $50(39.7)$ \\
\hline Fatigability & 1.12 & 1 & $47(37.3)$ \\
\hline Dissatisfaction & 0.95 & 0 & $40(31.7)$ \\
\hline Sadness & 0.9 & 1 & $38(30.2)$ \\
\hline Alcohol & 0.88 & 0 & $37(29.4)$ \\
\hline Body image changes & 0.79 & 1 & $33(26.2)$ \\
\hline Loss of libido & 0.79 & 0 & $33(26.2)$ \\
\hline Stomatic preoccupation & 0.76 & 0 & $32(25.4)$ \\
\hline Expectation of punishment & 0.38 & 0 & $16(12.7)$ \\
\hline Pessimism & 0.33 & 0 & $14(11.1)$ \\
\hline Crying & 0.31 & 0 & $13(10.3)$ \\
\hline Indecisiveness & 0.31 & 0 & $13(10.3)$ \\
\hline Irritability & 0.29 & 0 & $12(9.5)$ \\
\hline Guilt & 0.24 & 0 & $10(7.9)$ \\
\hline Self-dislike & 0.19 & 0 & $8(6.3)$ \\
\hline Sense of failure & 0.17 & 0 & $7(5.6)$ \\
\hline Drug indulgence & 0.17 & 0 & $7(5.6)$ \\
\hline Social withdrawal & 0.1 & 0 & $4(3.2)$ \\
\hline Self-accusations & 0.07 & 0 & $3(2.4)$ \\
\hline Suicidal ideas & 0.07 & 0 & $3(2.4)$ \\
\hline Gambling & 0 & 0 & $0(0)$ \\
\hline
\end{tabular}




\section{Appendix 11}

Five highest symptoms score verses study cases characteristics

\begin{tabular}{|c|c|c|c|c|c|}
\hline \multirow[t]{2}{*}{ Characteristic } & \multicolumn{5}{|c|}{ Five highest symptom scores (Mean) } \\
\hline & $\begin{array}{l}\text { Work } \\
\text { retardation }\end{array}$ & Insomnia & Anorexia & Fatigability & $\begin{array}{c}\text { Weight } \\
\text { Loss }\end{array}$ \\
\hline \multicolumn{6}{|l|}{ Age group (years) } \\
\hline $14-26$ & 2.18 & 1.18 & 0.91 & 0.91 & 0.82 \\
\hline $27-35$ & 1.82 & 1.27 & 1.45 & 1.18 & 1.09 \\
\hline $36-42$ & 1.67 & 0.83 & 1.08 & 1.00 & 1.33 \\
\hline $43-51$ & 1.64 & 0.82 & 1.09 & 1.00 & 1.18 \\
\hline $52-60$ & 1.50 & 0.90 & 0.80 & 1.10 & 0.70 \\
\hline $61+$ & 2.30 & 2.30 & 1.60 & 1.40 & 1.40 \\
\hline \multicolumn{6}{|l|}{ Tribe } \\
\hline Kamba & 2.38 & 1.46 & 1.15 & 1.46 & 1.15 \\
\hline Kikuyu & 1.69 & 1.42 & 1.15 & 1.04 & 0.92 \\
\hline Luhya & 2.00 & 0.75 & 1.00 & 1.25 & 1.25 \\
\hline Luo & 1.62 & 0.62 & 1.23 & 0.92 & 1.23 \\
\hline Others & 1.78 & 1.22 & 1.11 & 0.89 & 1.22 \\
\hline \multicolumn{6}{|l|}{ Last grade completed } \\
\hline Not educated & 2.06 & 1.78 & 1.22 & 1.28 & 1.17 \\
\hline Primary & 2.04 & 1.17 & 1.30 & 1.17 & 1.04 \\
\hline Secondary & 1.48 & 0.74 & 1.00 & 0.83 & 1.13 \\
\hline College & 2.00 & 2.00 & 0.00 & 2.00 & 0.00 \\
\hline \multicolumn{6}{|l|}{ Province of Birth } \\
\hline Nyanza & 1.60 & 0.73 & 1.20 & 0.87 & 1.20 \\
\hline Western & 2.00 & 0.75 & 1.00 & 1.25 & 1.25 \\
\hline Central & 1.67 & 1.48 & 1.19 & 1.07 & 1.00 \\
\hline Rift Valley & 2.00 & 0.75 & 1.00 & 0.50 & 1.00 \\
\hline Nairobi & 2.00 & 1.00 & 1.00 & 1.00 & 1.00 \\
\hline Eastern & 2.42 & 1.33 & 1.25 & 1.50 & 1.25 \\
\hline Coast & 2.00 & 2.00 & 0.50 & 1.50 & 0.50 \\
\hline \multicolumn{6}{|l|}{ Type of cancer } \\
\hline GIT & 1.57 & 1.36 & 1.07 & 1.21 & 1.29 \\
\hline Skin & 1.25 & 1.50 & 1.25 & 0.75 & 1.00 \\
\hline Blood and lymphnoid tissue & 1.64 & 1.36 & 1.09 & 1.36 & 1.00 \\
\hline Bone and muscle & 2.00 & 1.00 & 1.20 & 1.40 & 1.40 \\
\hline GUT & 1.50 & 2.00 & 1.50 & 1.50 & 1.50 \\
\hline Miscellaneous & 2.00 & 1.33 & 1.00 & 0.83 & 1.33 \\
\hline \multicolumn{6}{|l|}{ Treatment type } \\
\hline Surgery & 1.74 & 1.37 & 0.84 & 1.16 & 0.89 \\
\hline Radiotherapy & 1.74 & 1.37 & 0.84 & 1.16 & 0.89 \\
\hline Chemotherapy & 2.15 & 1.77 & 1.38 & 1.08 & 1.08 \\
\hline Combination & 1.93 & 0.73 & 0.80 & 1.20 & 1.13 \\
\hline Awaiting treatment & 2.00 & 1.17 & 2.17 & 1.00 & 1.33 \\
\hline
\end{tabular}

View of doctors: The majority of patients, $74 \%$ expressed that the doctors were trying their best to help them. Psychologist and psychiatrist review: Only one person $(2.4 \%)$ out of $42(100 \%)$ had contacted a psychiatrist. No person out of the 42 in the study had sought psychotherapy.

\section{DISCUSSION}

This study was conducted at the major referral and teaching hospital in Nairobi, Kenya. It aimed at establishing issues that influence the quality of life of a male cancer patient attributable to the cancer and factors that might influence such reactions.
The studied patients' characteristics of age distribution, peak age, tribal distribution, province of birth and level of education, appear to be consistent with the country's population. Also the observed malignancy patterns, histological types and anatomic sites are those commonly found in cancer in Kenya(16).

The observed outcome of the semi-structured questions was as expected varied(2,17). The chief complaints of the patients were inability to work, feeling miserable and pain. These appear to be consistent with other attributes found in this evaluation. It has been documented that physical symptoms are common to men with fears of the losses of career and part to the body(20). The main concerns expressed; related 
issues, family, health, work and finances. These are features which could be reported for any serious disease particularly life threatening disease $(19,21,22)$. In the absence of state organised social support and the low level of education of the study cases, there was bound to be concerns with regard to health, family, finances and treatment for any adult with a serious disease. Pain, which featured as a complaint and concern for the studied cases, is indeed a well-known association with cancer. Cancer pain can be due to anatomic site or type of cancer and can also be due to psychological issues regarding cancer. In this study like others, all these factors were the likely causes of pain expressed(23).

The coping response showed that $93 \%$ reported that they were unable to cope. Better coping was noted in the relatively young while poorer copers were observed to have a lower level or lack of education. In Kenya, the majority of the non-educated, primary and a proportion of secondary school graduates in the urban centres like the city of Nairobi are likely to depend on work requiring physical well being. This could offer some explanations as to why issues of work were widely expressed. Tribe patterns were a reflection of the province of birth results. These results also suggest that patients coping cues are far from being understood and may have not been adequately addressed in this group of patients.

The view on doctors showed that most patients, $76 \%$ thought that the doctors were doing their best while attending to them. The study further documented a larger proportion of these patients having received combination therapy of chemotherapy, surgery and radiotherapy and only a small proportion with only $10 \%$ still awaiting some form of treatment. Furthermore these were in-patients, which could have played positively in the patients' response.

Beck's depression inventory revealed an overall $20 \%$ depression. All the items except gambling scored at least a point in the cases evaluated. This implies that there was an aspect of depression in nearly all the evaluated items. Generally depression is noted to be common in cancer patients(24). In addition, it was observed that physical symptoms were pronounced and work retardation, insomnia, weight loss, anorexia and fatigability constituted the top five. The least five starting with the least were gambling, suicidal ideas, self-accusations, social withdrawal and drug indulgence.

Misery, which also featured in the study, was explained by patients to be due to their inability to work, pain, and concerns of health, family, finance and work as has been observed in other studies $(4,25)$. Of note is the low score on suicide tendency which is also consistent with what is generally observed in the Kenyan population (personal observation).

It is well documented that a majority of doctors avoided telling the patients the diagnosis because they thought the patient would commit suicide if he knows he has cancer $(6,7,19,22,26)$. Clearly the risk of suicide, as a result of discussing the patient diagnosis with him seems to be exaggerated. In this study, the score was only $3 \%$ for suicidal ideas, self-accusation, guilt and $1 \%$ for drug indulgence $(16,27)$.

The age groups and five most common symptoms show that except for those over 61 years old, work retardation was major in the older 52-60 years old. Those older than 61 years however showed consistency in the level of manifestations of most other symptoms of depression. Theoretically, at this age there are serious family concerns particularly for male head of households. Events occurring at this age are therefore likely to be widely ramified in terms of the family upkeep. Also showing consistency was the age group 27-35 years. However the 14-26 years manifested emphatically in work retardation and insomnia but much less with anorexia, fatigability and weight loss. These could be due to their general physical well being and aspects of social expectations.

The tribe and the five most manifested symptoms of depression tend to give the findings of the province of birth. The Eastern, Nairobi provinces appear consistent in the symptoms manifestations. Again the results showed little variation by province except for the Nairobi city exhibiting worst depression level as would perhaps be expected for any city life.

The level of education showed that those without education demonstrated worse symptoms compared with the others with various levels of education. Perhaps this is because of reduced opportunities for getting gainful occupation and dependence on physical well being.

Type of cancer results suggests that those with bone and muscle tumours, blood and Iymphoid tissue cancers had the strongest manifestations of work retardation, fatigability and weight loss. Studies from elsewhere have documented that although psychological investment occurs in all parts of the body, the head and neck is the most critical since it carries social interaction(23). Attractiveness, contact with others, affection and closeness to family and spouse begin with facial expression and appearance(28). However, in the current study, the prominence of those with gastrointestinal tract, insomnia, anorexia, fatigability and weight loss in relation to other sites is not easily explainable from the results obtained. The treatment type reveals that radiotherapy and those awaiting treatment expressed concerns with respect to work retardation, insomnia and anorexia(29). Compared to other modalities in this study there was most effects by chemotherapy arm being worse off compared to other types of treatment. Perhaps due to the fact that chemotherapy of cancer patient demands a high level of cooperation and high level of commitment by the patient both to accept treatment and to continue on what is often a stressful regimen. Some side effects have stressful sequelae and include generalized fatigue and weakness and disruption of work, home and daily routines $(18,19)$. 


\section{CONCLUSION}

Overall the results of the study revealed that there are issues which affected the quality of life in cancer patients in this setting and majority were psychological and coping with cancer. The factors that lead to disturbances in work, financial and physical well being of the patients appear to have far more potential to cause stressful responses than other aspects of life.

The shortcoming of this study included non-use of established quality of life instrument, relying on patients' perceptions and values of the symptoms issues presented to them. However, it does open a chapter in the management of cancer patients by our standards. It is clear therefore that further work is needed to enable improvement of quality of life during the management of cancer patients.

\section{ACKNOWLEDGEMENTS}

To the Director of Kenyatta National Hospital, Dr. F. M. Musau, who at the time of the study assisted in data collection and logistical issues. Also we extend thanks to Dr. Riro Muita who was the student collecting the data. Many thanks go to Mr. George K'opiyo for his assistance and Ms. Emma Onyango for secretarial assistance. This project would not have been successful without the help of the staff of adult radiotherapy oncology ward at $\mathrm{KNH}$ and special thanks to them all.

This work was supported in part by the centre for AIDS Research at Case Western Reserve/University Hospitals of Cleveland (AI-36219).

\section{REFERENCES}

1. Tierney, W.M. and McKinley, E.D. When the physician researcher gets cancer. Understanding cancer: its treatment and quality of life from the patient's perspective. Med. Care. 2002; 40:(Suppl 6)111-128.

2. Hollan, J.C. Psychologic aspects of cancer, Cancer Medicine 2nd Ed New York 1982 Jane F.H, EMILF XVI, 1175-1203

3. Pschosocial aspects of cancer UICG, International Union Against Cancer Manual of Clinics oncology pg 129-131 4th edition. C.D Sherman, K.C. Calman, S. Eckhaedrt; I isebai, D. Firat, D.K. Hassfield, J. Paunier, B. SAlvadori, SPrinter-Verlag Berlin Heidelberg New York.

4. Manos, N. and Christakis, J. Coping with cancer: psychological dimensions. Acta Psych. Scan. 1985; 721:1-5.

5. Tsevat, J. Cook, E.F., Green, M.L and Matchar, D.B. Health value for the seriously ill. Ann Int. Med. 1995; 122:514-520.

6. Farberow, N.L. Ganzel, S., Cutter, F. and Reynolds, B. An eight-year survey of hospital suicides. Life threatening Behaviour. 1971; 1:184-185.

7. Andersen, B. Psychological interventions of cancer patients to enhance the quality of life. J. Consulting Clinical Psych. 1992; 60:552-568.

8. Ubel, P.A., Jepson, C. and Baron, J. The inclusion of patient testimonials in decision making aids: Effects on treatment choices. Med. Decis. making. 2001; 21:60-68.

9. Ashbury, F.D., Findlay, H., Reynolds, B. and Mckerrcher, K. A Canadian survey of cancer patients' experiences: Are their needs being met? J. Pain Symptom Manag. 1998; 16:298-306.

10. Walker, M. S., Ristvedt, S. L. and Haughey, B.H. Patient care in multidisciplinary cancer clinics: does attention to psychosocial needs predict patient satisfaction? Psychooncology. 2003; 3:291-300.

11. Benyamini, McClain C. S., Leventhal, E. A. and Leventhal H. Living with the worry of cancer health perceptions and behaviours of elderly people with self. Vicarious or no history of cancer. Psycho-oncology. 2003; 12:161-172.

12. Znajda, T. L., Wunder, J. S., Bell, R. S. and Davis, A. M. General issues in patients with extremity soft tissue sarcoma a pilot study cancer. Nurs. 1999; 22:111-118.

13. Widdershovern, G. and Berghmans, R. Advanced directive in psychiatric care: A narrative approach. J. Med. Ethics. 2001; 27:92-97.

14. Fox, B. Premorbid psychological factors as related to cancer incidence J. Behav. Med. 1978; 1:45.

15. Artiso, L.K. and Levine, A.S. Doctor-patient relation in severe illness; a seminar for oncology fellows. New Eng. J. Med. 1973; 288:1210.

16. Zung, W.W.K., A self-rating depression scale. Arch. Gen. Psych. 1965; 12:60-70.

17. Ubel, P.A., Loewenstein, G. and Jepson, C. Whose quality of life? A commentary exploring discrepancies between health state evaluations of patients and the general public. Quality of Life Res. 2003; 12:599-520.

18. Achte, K. and Vauhkonen, M.L. Cancer and the Psych. Omega. 1971; 2:46-54.

19. Surawicz, F.G; Brightwell. D. R; Weitzcs, W. and Othmer E. Cancer, emotions and mental illness the present state of understanding. Amer. J. Psychiat. 1976; 133:1306-1314.

20. DeFlorio, M. and Masie, M.J. Review of depression in cancer: gender differences. Depression. 1995; 3:66-80.

21. Sellik, S.M. and Crooks, D.L. Depression and cancer: An appraisal of the literature for prevalence, detection, and practice guideline development for psychological interventions. Psycho-Oncology. 1999; 8:315-333.

22. Farberow, N.L., Schneidman, E.S. and Leonard, C.V. Suicide among general medical and surgical hospital patients and those with malignant neoplasm. Med. Bull Veterans Admin. 1963; 9:1.

23. Zebora, J., BrintzenhofeSzoc, K., Curbow, B., Hooker, C. and Piantadosis S. The prevalence of psychological distress by cancer site. Psycho-oncology. 2001; 10:19-28.

24. Strain, J.J. Adjustment Disorders. In Psycho-oncology (Edited by: Holland JF) New York: Oxford University Press. 1998; 509-517.

25. Massie, M.J. and Popkin, M.K. Depressive Disorders. In Psycho-oncology (Edited by: Holland J.F.) New York: Oxford University Press. 1998; 518-540.

26. Derogatis, L.R., Morrow, G.R. and Fetting, J. The prevalence of psychiatric disorders among cancer patients. J. Amer. Med. Ass. 1983; 249:751-757.

27. Noyes, R., Holt, C.S. and Massie, M.J. Anxiety Disorders. In Psycho-oncology (Edited by: Holland JF) New York: Oxford University Press 1998; 548-563.

28. Butow, P. W., Brown, R. F., Cogar, S., Tattershall, M. H. and Dunn, S. M. Oncologist reactions to cancer patients' verbal cues. Psycho-oncology. 2002; 11:147-58.

29. Jansen, S.J., Kievit, J. Nooij, M.A. and Stiggelbout, A.M. Stability of patients' preferences for chemotherapy: The impact of experience. Med. Decis Making 2001; 21:295-306. 